\title{
Research on the Vibration Damping Performance of a Novel Single-Side Coupling Hydro- Pneumatic Suspension
}

\author{
Xuefeng SUO*, Shengjie JIAO, Gangfeng WANG, Simeng LIU, Zeyu ZHANG
}

\begin{abstract}
A mine dump truck is exposed to heavy load and harsh working environment. When the truck passes over the road bumps, it will cause the body to tilt and the tires to "jump off the ground" (JOTG), which will affect the stability and safety of the truck, and will cause impact damage to the body and suspension system. To avoid this situation, a kind of Novel Single-side Coupling Hydro-pneumatic Suspension (NSCHs) is presented. NSCHs consists of two cylinders in parallel, which are connected to the accumulator by rubber pipes and mounted on the same side of the dump truck. Theoretical analysis and experimental research were respectively carried out under the road and loading experimental condition. The experimental results show that compared to the conventional single cylinder hydro-pneumatic suspension, under the loading experiment condition, the maximum overshoot pressure of the NSCHs was reduced by $0.4 \mathrm{MPa}$ and the impact oscillation time was shortened by $4.13 \mathrm{~s}$, which plays the effective role in reducing vibration and absorbing energy. Further, it is found that the two cylinders are coupled during the working process, and the NSCHs system can achieve uniform loading and displacement compensation, thus the novel dump truck can avoid the occurrence of the JOTG phenomenon.
\end{abstract}

Keywords: displacement compensation; hydro-pneumatic suspension; mine dump truck; response time; single-side coupling

\section{INTRODUCTION}

Mine dump truck is exposed to heavy load, complex working conditions and poor road surface. When a truck is driven on uneven road, it causes the body to tilt, affecting the vehicle driving stability seriously, and will cause rolling over. When the truck passes over a convex platform on the road the tire "jump off the ground" phenomenon may appear, landing will produce a huge impact force, which will cause damage to the body. The suspension plays a key role in reducing vibration and absorbing energy. In recent years, hydro-pneumatic suspension with its advantages of nonlinear stiffness and nonlinear damping has been widely used in vehicles, and scholars carried out in-depth research.

The ride comfort of the vehicle is an issue that people are very concerned about [1-4], the suspension is a key component that affects the ride comfort. Anirban. C. Mitra et al. [5] established four-degree-of-freedom model and used the simulation software SIMULINK to analyse the ride comfort, optimized vehicle ride comfort with Genetic algorithm. Kyuhyun Sim et al. [6] to improve the ride comfort of an agricultural tractor, a hydro-pneumatic suspension model with a semi-active suspension control is developed with computer simulation, and the effectiveness of the suspension is evaluated before the vehicle is equipped with the suspension and placed into production. M. Zehsaz et al. [7] studied the effects of different vibration frequencies on human health. By using experimental measurements and finite element analysis, the purpose of improving the riding comfort of tractor was achieved by changing the suspension parameters. Enlai Zheng et al. [8] established three-dimensional dynamic model of the wheeled tractor/implement system with a front axle hydropneumatic suspension. Consider the effect of implement and passive rub cabin suspension as well as front axle hydro-pneumatic, Investigation into the vibration characteristics of agricultural wheeled tractor-implement system with hydro-pneumatic suspension on the front axle.

Hydro-pneumatic suspension parameters will affect its stiffness and damping, and it is very important to choose proper parameters to improve suspension performance.
Lalitkumar Maikulal Jugulkar et al. [9] analysed the influence of stiffness and damping on the vibration damping performance, and verified through the simulation that choosing the appropriate stiffness and damping can improve the ride comfort of the vehicle. Jugulkar L. M. et al. [10] presented a variable stiffness system, which comprises two helical springs and a variable fluid damper. Fluid damper intensity is changed in four discrete levels to achieve variable stiffness. Numerical simulation results on the real size model indicate the peak acceleration will improve by $15 \%$ in comparison to the conventional passive solution, without significant deterioration of road holding ability.

The accumulator is a key component of hydropneumatic suspension, the gas in it plays an elastic role [11], and some scholars have done special research on it. Yuming Yin et al. [12, 13] studied the emulsification phenomenon of hydro-pneumatic suspension, and concluded that the higher the pressure is, the more gas will enter the oil and the emulsification phenomenon will be more obvious. Finally, the effective stiffness of the suspension increases and the damping decreases. S. Francois van der Westhuizen et al. [14, 15] compared different gas models to calculate the spring force of the hydro-pneumatic suspension. This study compares the performance of three ideal gases (IG) with the energy equation, Benedict Webb Rubin (BWR) equation with and without the energy equation (EE). These models are compared with experimental results. Both the BWR and IG models with the EE offer a significant improvement in correlation compared to the models without the EE. The real gas BWR approach offers a small improvement over the IG approach under the test conditions.

The above referred scholars carried out simulation analysis and experimental research on the hydropneumatic suspension, and evaluated the influence of different parameters of hydro-pneumatic suspension on the suspension stiffness and damping, as well as the vehicle riding comfort under different working conditions. In order to improve the performance of the suspension, active suspension and semi-active suspension are proposed [1619]. 
The structure of traditional single-cylinder hydropneumatic suspension (CSCHs) is simple and easy to install, because of its advantages of nonlinear stiffness and nonlinear damping, it can reduce vibration and absorb energy at different loads of vehicle. But the CSCHs cannot solve the following problems: (1) Vehicle body tilting when the vehicle is driving on the uneven road. (2) When the vehicle passes over a convex platform it will result in tire off the ground, which will generate huge impact force. Therefore, this paper presented a kind of novel single-side coupling hydro-pneumatic suspension (NSCHs). The output force and the stiffness of it are studied by theoretical analysis, the vibration and energy absorption characteristics of NSCHs are researched through road and loading experiment.

The present paper is structured as follows. In Section 2 we introduce the structure and working principle of the NSCHs, and analyse its output force and stiffness. Section 3 designs the experimental schemes of the road experiment and the loading experiment. Section 4 analyses the experimental results, obtained advantages of the NSCHs by comparing with the CSCHs. Finally, Section 5 presents the conclusion and future work.

\section{HYDRO-PNEUMATIC SUSPENSION STRUCTURE AND ANALYSIS}

Based on the conventional single cylinder hydropneumatic suspension, a kind of novel single-side coupling hydro-pneumatic suspension is presented, and its output force and stiffness are analysed theoretically.

\subsection{Conventional Single-Cylinder Hydro-Pneumatic Suspension (CSCHs)}

The internal structure of the CSCHs is shown in Fig. 1. It is composed of cylinder, piston rod and energy accumulator. The piston rod is connected to the wheel, which has a damping hole and a check valve to act as a shock absorber. The suspension consists of three cavities: I $\sim$ III. The cavity I and cavity II are filled with oil, cavity III (energy accumulator) consists of two parts, the lower is the oil, the upper is the inert gas, the gas and oil are separated by an airbag, which can prevent the inert gas dissolving into the oil at high temperature and high pressure, the inert gas acts as an elastic element [20].

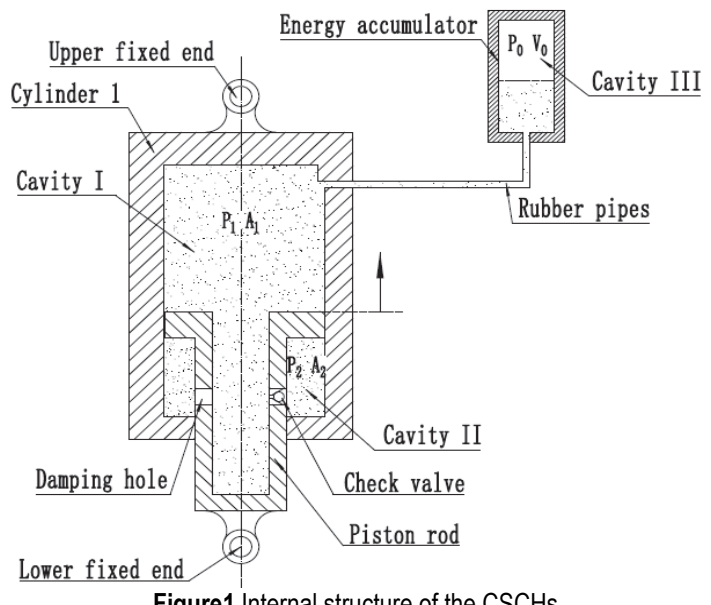

Figure1 Internal structure of the CSCHs
The truck is driven on uneven road; the cylinder reduces the vibration absorption energy by stretching and compression. When the CSCHs is in the compression stroke, the oil in cavity I flows into cavity II through the check valve and the damping hole, at the same time a part of oil flows into the accumulator through the rubber pipes and then compresses the gas, which results in the increment of the gas pressure. The energy accumulator plays an elastic role.

When the CSCHs is in the stretching stroke, the oil in cavity II flows into cavity I through the damping hole, and the check valve is closed, producing a large damping force and quickly absorbing energy attenuation vibration.

The initial pressure of gas in the accumulator is $P_{0}$, the initial volume is $V_{0}, P_{\mathrm{c}}$ is the pressure of the gas in a certain state, and $V_{\mathrm{c}}$ is the volume of the gas in the corresponding state, $r$ is the poly-tropic co-efficient. Ignoring the temperature change of gas, according to the ideal gas state equation, one can get:

$$
\begin{aligned}
& P_{\mathrm{c}} V_{\mathrm{c}}^{r}=P_{0} V_{0}^{r}=\mathrm{const} \\
& V_{\mathrm{c}}=V_{0}-\left(A_{1}-A_{2}\right) x
\end{aligned}
$$

where $A_{1}$ is the area of the cavity I, $A_{2}$ is the area of the cavity II, $x$ is the displacement of the piston relative to the balance position, the upward is positive direction and the downward is negative direction.

Substituting Eq. (2) in Eq. (1) one gets

$$
P_{c}=\frac{P_{0} V_{0}^{r}}{\left[V_{0}-\left(A_{1}-A_{2}\right) x\right]^{r}}
$$

The output force of the CSCHs is as follows:

$$
F_{\mathrm{k}}=P_{c}\left(A_{1}-A_{2}\right)=\frac{P_{0} V_{0}^{r}\left(A_{1}-A_{2}\right)}{\left[V_{0}-\left(A_{1}-A_{2}\right) x\right]^{r}}
$$

Differentiate can get the stiffness coefficient of the CSCHs:

$$
K(x)=\frac{\mathrm{d} F_{\mathrm{k}}}{\mathrm{d} x}=\frac{r P_{0} V_{0}^{r}\left(A_{1}-A_{2}\right)^{2}}{\left[V_{0}-\left(A_{1}-A_{2}\right) x\right]^{r+1}}
$$

It can be seen that the stiffness coefficient is related to $A_{1}, A_{2}, P_{0}, V_{0}$ and $x$. For the deterministic suspension $A_{1}, A_{2}$, $P_{0}, V_{0}$ are constant, so the stiffness coefficient and $x$ are nonlinear.

\subsection{Novel Single-Side Coupling Hydro-Pneumatic Suspension (NSCHs)}

The NSCHs is made of two cylinders in parallel, mounted on the same side of the vehicle, as shown in Fig. 2. Cylinder 2 and cylinder 3 are connected to the accumulator by rubber pipes, the accumulator is filled with high-pressure $N_{1}$, which is separated from the oil by an airbag to prevent the gas dissolving into the oil under high 
temperature and pressure.

When the wheel connected to cylinder 2 passes over a convex platform on the road, Cylinder 2 is in the compression stroke, some oil in cavity A will flow in three directions simultaneously due to the piston thrust forces. That is, one part of the oil in cavity A enters cavity B through damping hole 1 and check valve 1, generating a small damping force; another part flows into the accumulator through the rubber pipes, compressing the gas in cavity $\mathrm{C}$; and the other part flows into the cavity $\mathrm{E}$ through rubber pipes, resulting in a stretching stroke in cylinder 3 .

When the wheel connected to cylinder 2 passes over a a concave on the road, the cylinder 2 is in the stretching stroke, the oil in cavity B flows to cavity A through the damping hole 1 , the check valve 1 is closed, which can generate a big damping force; at the same time, the oil in both the accumulator and cavity $\mathrm{E}$ flows into cavity $\mathrm{A}$ through rubber pipes, which result in cylinder 3 being in a compression stroke.

Thus it can be seen that the motion direction of two cylinders is always opposite, so they cooperate to absorb energy quickly and compensate displacement.

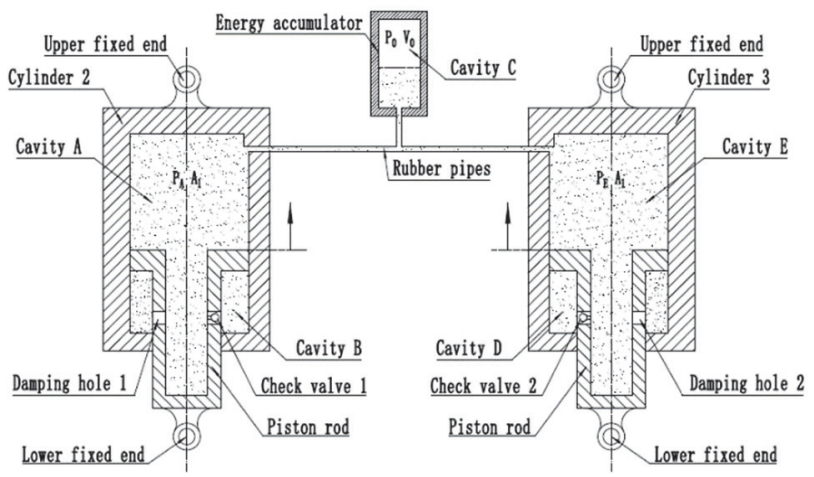

Figure 2 The structure of the NSCHs

In order to compare the performance of the NSCHs and the $\mathrm{CSCHs}$, the following experimental conditions were selected: Cylinder 1, cylinder 2 and cylinder 3 have the same structure and size. The accumulator of the NSCHs is the same as that of CSCHs, the gas initial pressure is $P_{0}$, initial volume is $V_{0}$, and the change of gas temperature is ignored. One can get from the ideal gas state equation:

$P_{\mathrm{d}} V_{\mathrm{d}}^{r}=P_{0} V_{0}^{r}=\mathrm{const}$

where $P_{\mathrm{d}}$ is the pressure of the gas in accumulator at a certain state, and $V_{\mathrm{d}}$ is the volume of the gas in the corresponding state. follows:

The compressed volume of the accumulator is as

$$
V_{\mathrm{d}}=V_{0}-\left(A_{1}-A_{2}\right)\left(x_{\mathrm{f}}+x_{\mathrm{r}}\right)
$$

where $x_{\mathrm{f}}$ is the displacement of cylinder $2, x_{\mathrm{r}}$ is the displacement of cylinder 3 , upward is positive direction, downward is negative direction.

The pressure of the gas in accumulator at the corresponding state is as follows:

$$
P_{\mathrm{d}}=\frac{P_{0} V_{0}^{r}}{\left[V_{0}-\left(A_{1}-A_{2}\right)\left(x_{\mathrm{f}}+x_{\mathrm{r}}\right)\right]^{r}}
$$

The output force of the NSCHs can be obtained as follows:

$$
F_{\mathrm{d}}=P\left(A_{1}-A_{2}\right)=\frac{P_{0} V_{0}^{r}\left(A_{1}-A_{2}\right)}{\left[V_{0}-\left(A_{1}-A_{2}\right)\left(x_{\mathrm{f}}+x_{\mathrm{r}}\right)\right]^{r}}
$$

It can be seen that the size of $F_{\mathrm{d}}$ is related to parameters $x_{\mathrm{f}}$ and $x_{\mathrm{r}}$, because when cylinder 2 is compressed, cylinder 3 is stretched, and vice versa.

When the compression of cylinder 2 is the same as cylinder $1, x=x_{\mathrm{f}}, F_{\mathrm{k}}>F_{\mathrm{d}}$.

The stiffness coefficient of the NSCHs can be obtained by solving the partial derivative of $F_{\mathrm{d}}$ with respect to $x_{\mathrm{f}}$.

$$
K_{\mathrm{f}}(x)=\frac{\partial F_{d}}{\partial x_{\mathrm{f}}}=\frac{r P_{0} V_{0}^{r}\left(A_{1}-A_{2}\right)^{2}}{\left[V_{0}-\left(A_{1}-A_{2}\right)\left(x_{\mathrm{f}}+x_{\mathrm{r}}\right)\right]^{r+1}}
$$

The two cylinders of NSCHs are connected in parallel, it is equivalent to two springs in parallel, and the spring stiffness coefficient is the same, which can play a role of uniform load when working.

\section{EXPERIMENTAL SCHEME DESIGN}

In order to analyse the vibration damping performance of the NSCHs, a $6 \times 4$ mine dump truck is used for experimental research, as shown in Fig. 3. The front suspension of the truck adopts CSCHs, while the middle and rear suspension adopt the NSCHs.

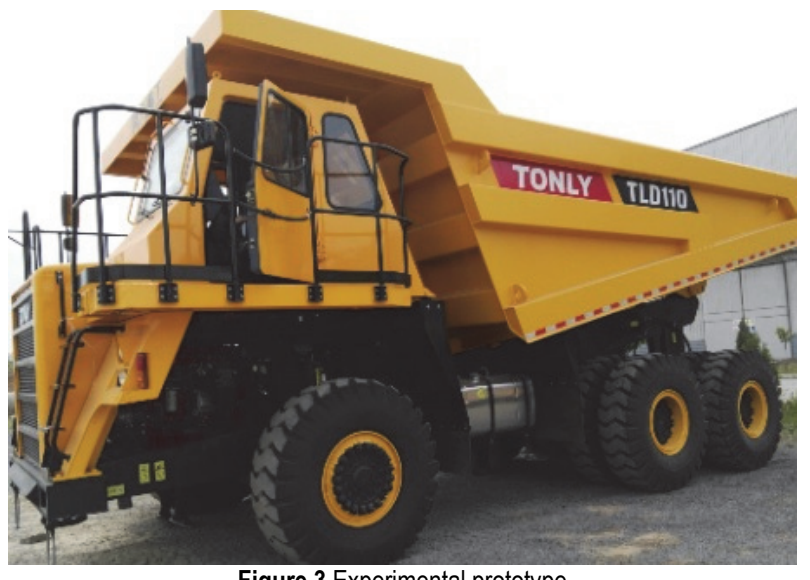

Figure 3 Experimental prototype

Fig. 4 shows the layout of NSCHs: The accumulator is fixed on the bridge which is connected to the cylinder through rubber pipes. One pipe is connected to cylinder 2, which is connected to the middle wheel. The other pipe is connected to cylinder 3 , which is connected to the rear wheel.

There are two experimental conditions: the road and the loading experiment, with the pressure and the displacement of the suspensions measured respectively. 


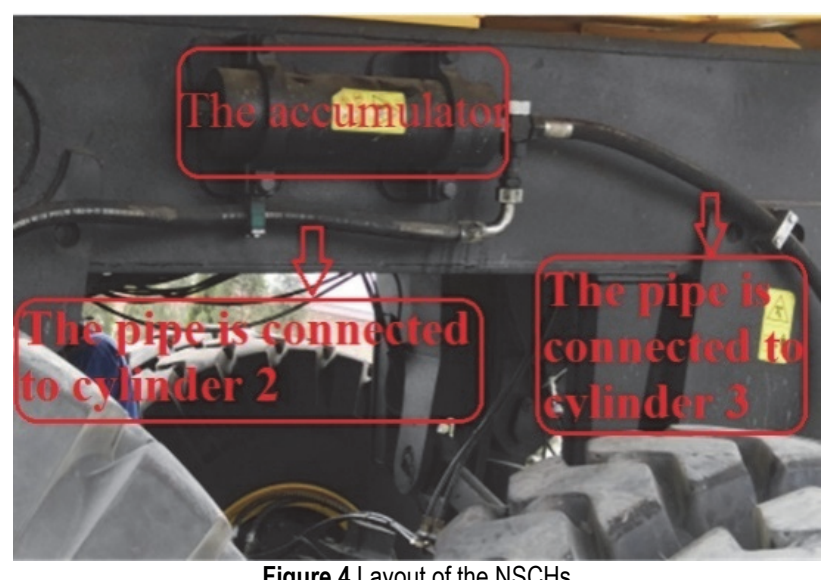

Figure 4 Layout of the NSCHs

\subsection{Experimental Equipment and Sensors Arrangement}

The experimental equipment adopts the DEWE-2600 multi-channel data signal acquisition instrument. The pressure sensors and displacement sensors were installed on the hydro-pneumatic suspension, as shown in Fig. 5.

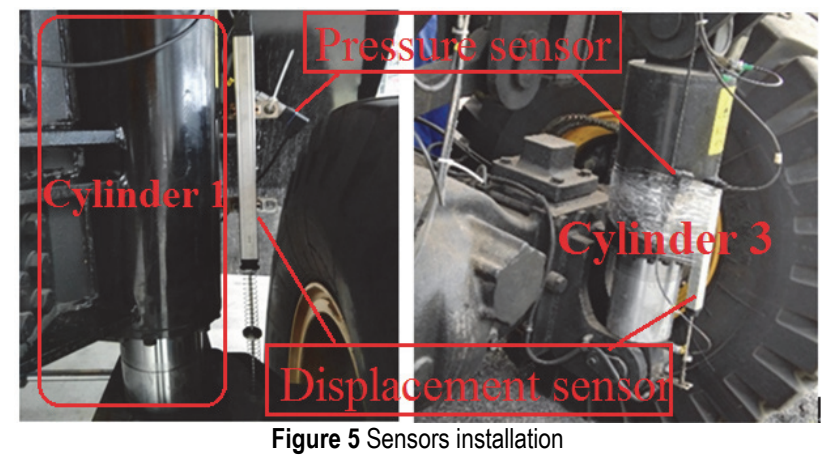

The main equipment of the experiment included the following: experimental truck, data acquisition equipment, pressure sensors and displacement sensors. The equipment parameters and quantities are shown in Tab. 1.

\begin{tabular}{|c|c|c|}
\hline $\begin{array}{c}\text { Experimental } \\
\text { equipment }\end{array}$ & Pable 1 Experimental equipment list & Amount \\
\hline TLD110 & $6 \times 4$ form, vehicle weight: $40 \mathrm{t}$ & 1 \\
\hline $\begin{array}{c}\text { the DEWE-2600 } \\
\text { multi-channel data } \\
\text { signal acquisition } \\
\text { instrument }\end{array}$ & 16 channel & 1 \\
\hline $\begin{array}{c}\text { Pressure sensor } \\
\text { Measuring range: } 0 \sim 40 \mathrm{MPa}, \\
\text { Accuracy: } \pm 0.2 \%\end{array}$ & 6 \\
\hline $\begin{array}{c}\text { Type: NS - WY03 } \\
\text { Displacement } \\
\text { sensor }\end{array}$ & $\begin{array}{c}\text { Measuring range: } 0 \sim 500 \mathrm{~mm}, \\
\text { Comprehensive accuracy: } \pm 0.1 \% \mathrm{~F} . \mathrm{S}\end{array}$ & 6 \\
\hline
\end{tabular}

\subsection{The Road Experimental Condition}

The cement road was selected for experiment, as shown in Fig. 6. The convex platform with the height of $120 \mathrm{~mm}$ is set at the middle of the road. The shape of the convex platform is shown in Fig. 7.

In order to verify whether the tire JOTG phenomenon occurs when the truck passes over the convex platform, the speed is selected as $5 \mathrm{~km} / \mathrm{h}$ and $15 \mathrm{~km} / \mathrm{h}$.

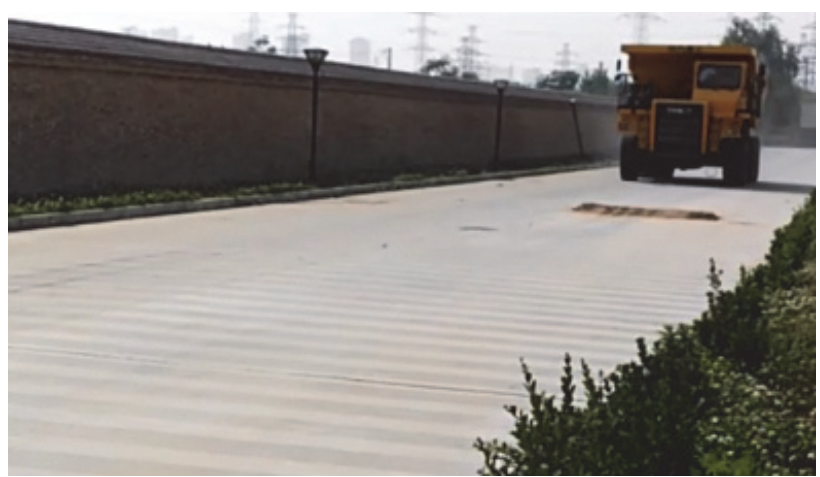

Figure 6 Experimental road

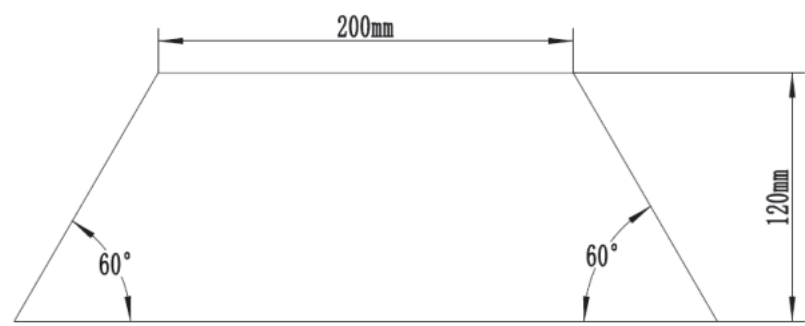

Figure 7 Shape of the convex platform

\subsection{Loading Experimental Condition}

The loading will generate a great impact force, which easily damages the suspension of the truck, so the pressure of both CSCHs and NSCHs was tested during loading [21, 22].

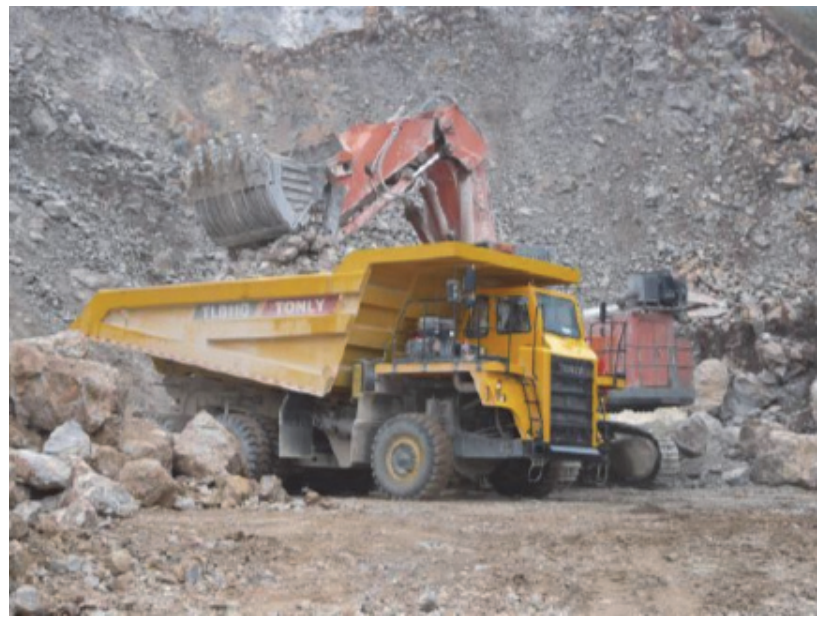

Figure 8 Loading experiment site

During the loading process the material hits the truck body, results in the highest magnitude of the impact force, then attenuates, and finally tends to a stable value.

The potential energy of material is converted into pressure energy and internal energy, the pressure energy is stored in the accumulator, internal energy is dissipated as heat $[23,24]$.

The gravitational potential energy is given as follows.

$W=m g h$

where $W$ is the gravitational potential energy, $m$ is loading mass, in this experiment $m=1000 \mathrm{~kg}, h$ is the falling height of the charging, in this experiment $h=2 \mathrm{~m}, \mathrm{~g}$ is the gravitational acceleration. 
According to the law of conservation of energy:

$W=E_{\mathrm{p}}+E_{\mathrm{c}}=\mathrm{const}$

where $E_{\mathrm{p}}$ is pressure energy, $E_{\mathrm{c}}$ is internal energy.

\section{RESULTS AND DISCUSSION}

The actual experiment was adopted to obtain the pressure and displacement changes of hydro-pneumatic suspension under different working conditions, the performance of NSCHs and CSCHs was analysed, which can reflect the performance of suspension more truly.

\subsection{The Road Experimental Results and Analysis}

When the Mine dump truck passes over the convex platform at the speed of $5 \mathrm{~km} / \mathrm{h}$, the measured displacement of the CSCHs is shown in Fig. 9.

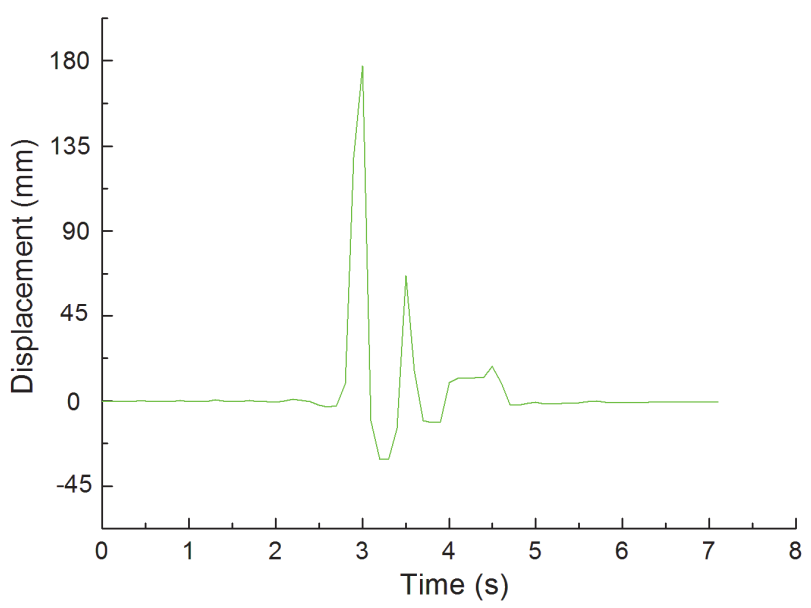

Figure 9 Displacement of the CSCHs when the speed is $5 \mathrm{~km} / \mathrm{h}$

As can be seen from Fig. 9, the displacement of the CSCHs changes continuously, without the tire JOTG phenomenon.

When the truck passes over the convex platform at the speed of $15 \mathrm{~km} / \mathrm{h}$, the measured displacements of the CSCHs and NSCHs are shown in Fig. 10. It can be seen that the displacement change of the CSCHs shows "stagnation" phenomenon, i.e. the tire experiences JOTG, time off the ground is 0.2 seconds.

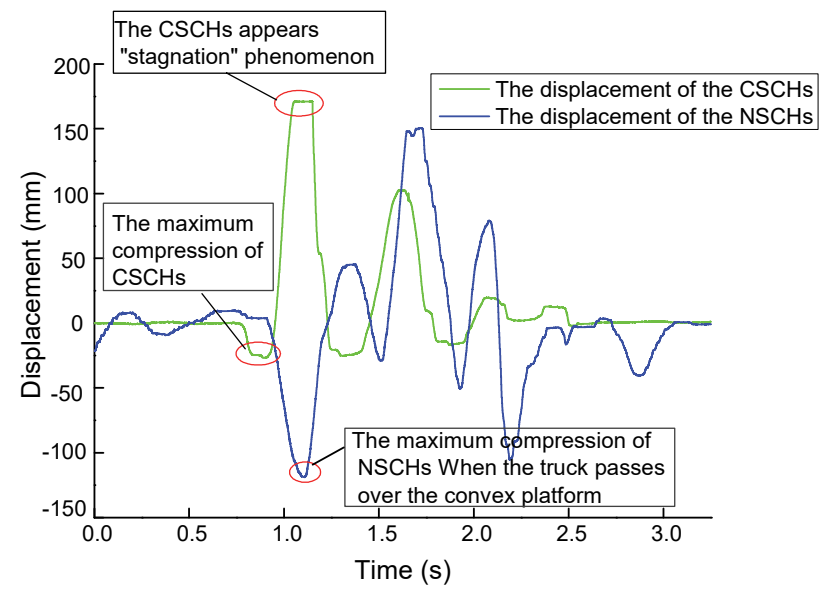

Figure 10 Displacement of the suspension when the speed is $15 \mathrm{~km} / \mathrm{h}$
Through comparison, it can be seen that the tire JOTG is related to the speed: the faster the truck travels, the more likely it is to have tires off the ground.

Fig. 10 shows the displacement of both $\mathrm{CSCHs}$ and NSCHs when the vehicle passes over the convex platform. It can be seen that when the wheel is on the convex platform the compression of the CSCHs is only $30 \mathrm{~mm}$, because the height of convex platform is $120 \mathrm{~mm}$, which results in this wheel being taller than others, eventually leading to the truck tilt. When the middle wheel is on the convex platform, the compression of the NSCHs is $120 \mathrm{~mm}$, and the truck has no obvious tilt. It can be seen that the NSCHs can help the truck maintain a better body posture.

The pressure changes of the CSCHs and the NSCHs when the truck passed over the convex platform at the speed of $15 \mathrm{~km} / \mathrm{h}$ are shown in Fig. 11.

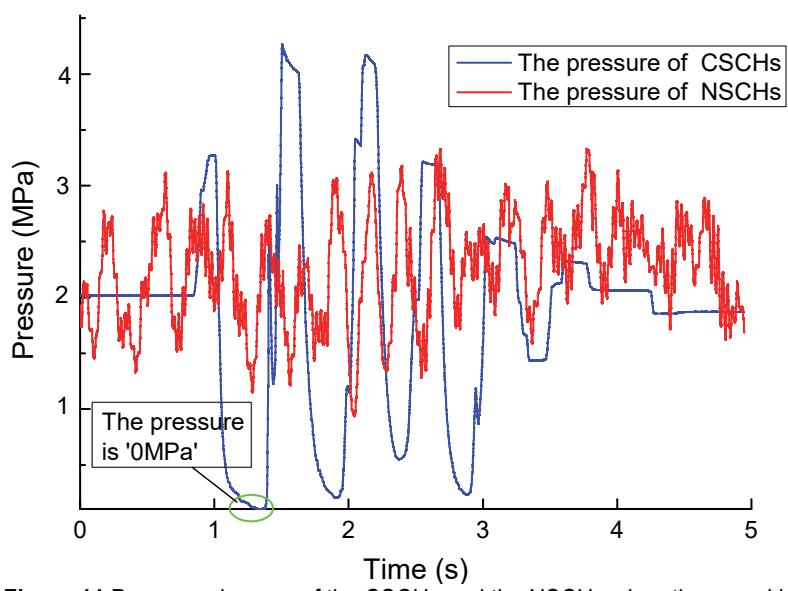

Figure 11 Pressure changes of the $\mathrm{CSCHs}$ and the NSCHs when the speed is $15 \mathrm{~km} / \mathrm{h}$

It can be seen from Fig. 11, there is a short time that the pressure of $\mathrm{CSCH}$ is "0 $\mathrm{MPa}$ ", at this time the tire jumps off the ground, the pressure increases rapidly after the tire landing. However, the pressure of the NSCHs changes continuously without any sudden change and the peak pressure is obviously smaller than that of the CSCHs.

When one cylinder of the NSCHs is compressed, the oil in the cylinder will flow to another cylinder through the rubber pipes, making it in a stretched state. The two cylinders coordinate with each other for displacement compensation, so as to avoid the phenomenon of tires off the ground.

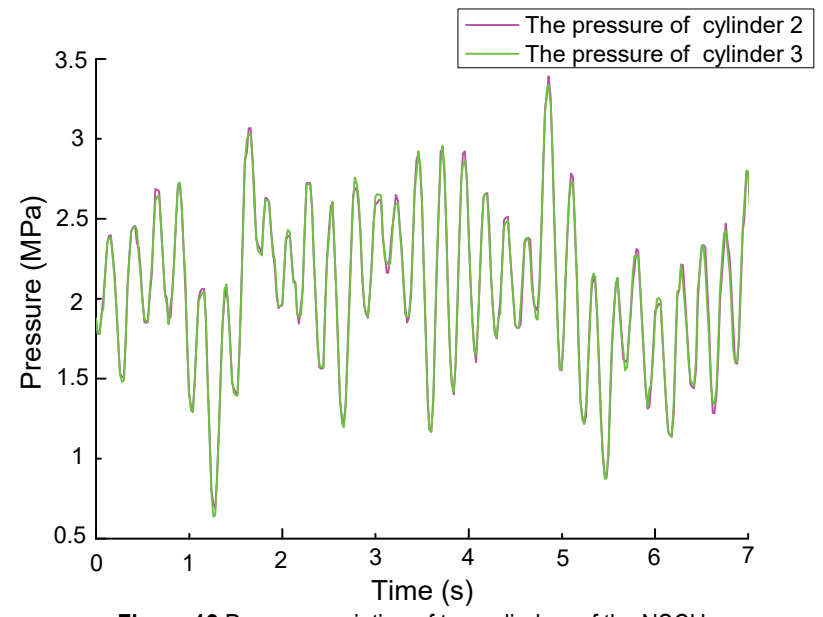

Figure 12 Pressure variation of two cylinders of the $\mathrm{NSCHs}$ 
During the driving of the truck, the pressure variation curves of the two cylinders of the NSCHs are shown in Fig. 12.

The pressure of the two cylinders is almost the same, so the NSCHs solves the problem of uniform loading.

To further study the pressure consistency of the two cylinders, the pressure difference between cylinder 2 and cylinder 3 was calculated, as shown in Fig. 13.

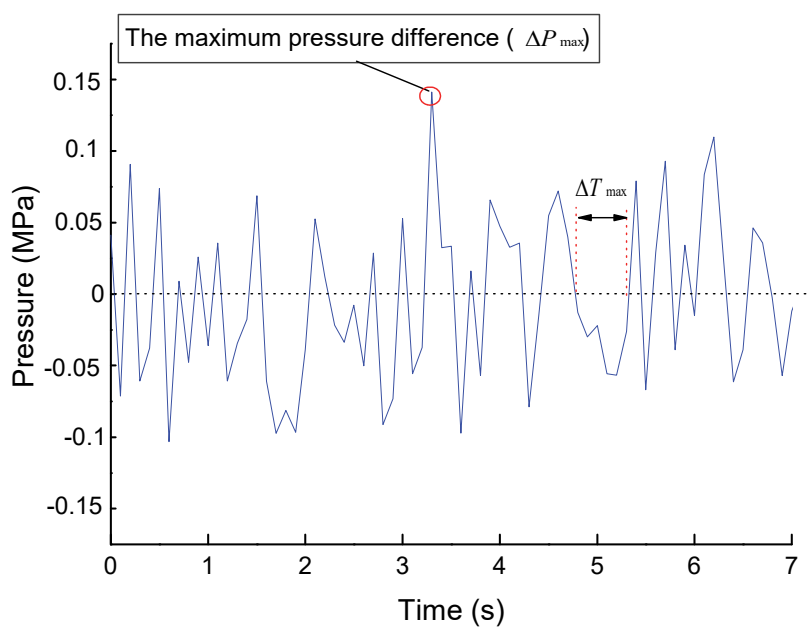

Figure 13 Pressure difference between cylinder 2 and cylinder 3

The Eq. (13) is utilized to calculate the pressure difference between cylinder 2 and cylinder 3 , as shown in Fig. 13.

$$
\begin{aligned}
& \Delta P=P_{\mathrm{E}}-P_{\mathrm{A}} \\
& \Delta P_{\max }=\max (\Delta P)
\end{aligned}
$$

where $P_{\mathrm{A}}$ is the pressure of cylinder $2, P_{\mathrm{E}}$ is the pressure of cylinder $3, \Delta P$ is the difference between cylinder 2 and cylinder $3, \Delta P_{\max }$ is the maximum value of $\Delta P$.

$\Delta T_{i}=T_{i+1}-T_{i}(i=1,2,3, \ldots, n)$

$\Delta T_{\max }=\max \left(\Delta T_{i}\right)(i=1,2,3, \ldots, n)$

where $T_{i+1}$ is the time when the $\Delta P_{i+1}$ is $0, T_{i}$ is the time when the $\Delta P_{i}$ is $0, \Delta T_{i}$ is response time, $\Delta T_{\max }$ is the longest response time.

The experimental results are shown in Tab. 2, during the driving process of the truck. The maximum pressure difference is $0.14 \mathrm{MPa}$, and the longest response time is $0.56 \mathrm{~s}$.

\begin{tabular}{|c|c|}
\hline Experimental parameters & Value \\
\hline The maximum pressure difference $\left(\Delta P_{\max }\right)$ & $0.14 \mathrm{MPa}$ \\
\hline The longest response time $\left(\Delta T_{\max }\right)$ & $0.56 \mathrm{~s}$ \\
\hline
\end{tabular}

Table 2 Statistics of the maximum pressure difference and the longest response

The two cylinders of the NSCHs are connected by rubber pipes, equivalent to two parallel springs, and the stiffness of the two springs is equal, so it plays a good role of uniform loading [25-28].

\subsection{The Loading Experimental Results and Analysis}

Fig. 14 presents the pressure changes of the $\mathrm{CSCHs}$ during loading. It can be seen that during the material falling into the truck, the pressure increases rapidly first and reaches the maximum value quickly, then attenuates, and finally tends to a stable value.

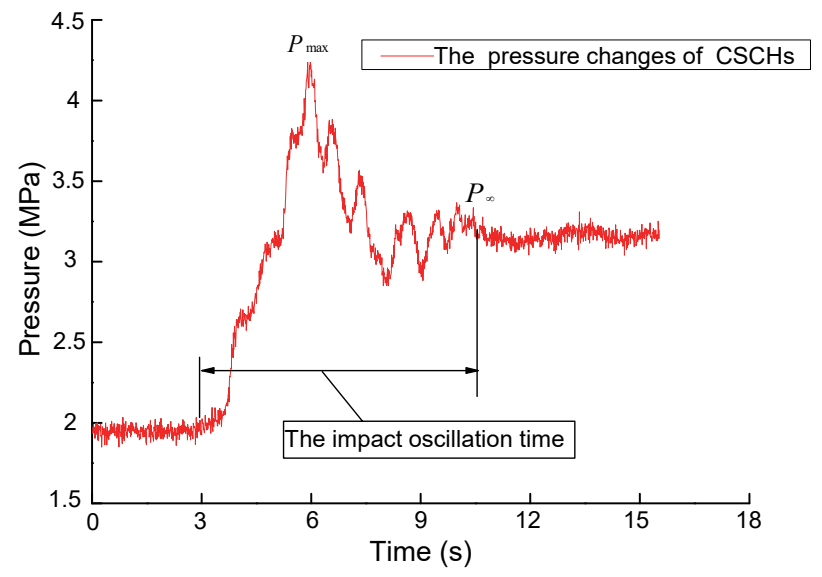

Figure 14 Pressure changes of the $\mathrm{CSCHs}$ during loading

During loading, the pressure change of the two cylinders (cylinder 2 and cylinder 3 ) of the NSCHs is shown in Fig. 15. It can be seen that the pressure change rule is the same as that of the CSCHs. The pressure also increases rapidly first and reaches the maximum value, then starts to attenuate, and finally tends to a stable value. The pressure of two cylinders is basically the same, which proves that the NSCHs also realized uniform load during the loading process.

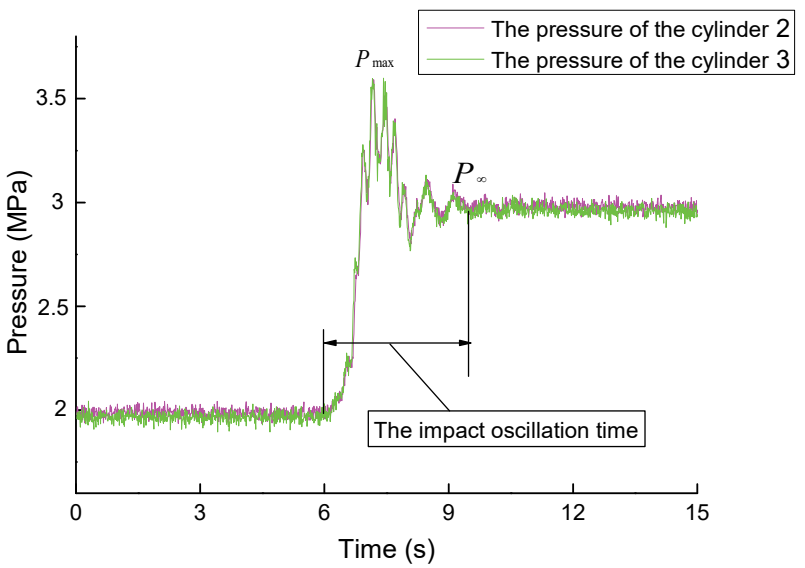

Figure 15 Pressure of the NSCHs change during loading

The maximum overshoot of pressure is given as follows:

$\Delta P=P_{\max }-P_{\infty}$

where $P_{\max }$ is the maximum pressure, $P_{\infty}$ is the pressure of the cylinder when the oscillation attenuation reaches the stable state, $\Delta P$ is the maximum overshoot of the pressure.

$T, \mathrm{~s}$ is impact oscillation time, which is the time from the pressure oscillation to reaching steady state.

As can be seen from Tab. 3, the maximum overshoot pressure of the CSCHs during loading is $1.08 \mathrm{MPa}$ and the 
impact oscillation time is $7.64 \mathrm{~s}$. The maximum overshoot pressure of the NSCHs is $0.68 \mathrm{MPa}$ and the impact oscillation time is $3.51 \mathrm{~s}$. Through comparison, it can be found that the maximum overshoot pressure of the NSCHs is smaller, the impact oscillation time is shorter, and the effect of vibration reduction and absorption energy is better.

Table 3 Statistics of the maximum overshoot pressure and the impact oscillation time during loading

\begin{tabular}{|l|c|c|}
\hline \multicolumn{1}{|c|}{ Suspension type } & $\Delta P / \mathrm{MPa}$ & $T / \mathrm{s}$ \\
\hline The CSCHs & 1.08 & 7.64 \\
\hline The NSCHs & 0.68 & 3.51 \\
\hline
\end{tabular}

\section{CONCLUSION AND PERSPECTIVE}

In this paper, the novel single-side coupled hydropneumatic suspension is presented. Theoretical analysis and experimental research were carried out. The results show that the NSCHs can avoid the tires off the ground phenomenon; displacement compensation between the two cylinders can avoid body tilt; it also has the advantages of fast response speed, good effect of vibration energy absorption and uniform load, the specific conclusions are as follows:

(1) When the truck is driving on uneven road, the two cylinders of the NSCHs can compensate each other for the displacement so as to avoid the body tilt and better maintain body posture.

(2) When the truck passes over the convex platform at a high speed, the NSCHs can avoid JOTG and can better protect the truck and suspension.

(3) The two cylinders of the NSCHs are connected to the accumulator by rubber tubing, equivalent to two parallel springs, and the pressure is basically the same, with the maximum pressure difference of $0.14 \mathrm{MPa}$ and the maximum response time $0.56 \mathrm{~s}$, to achieve the uniform loading.

(4) In the loading experiment, compared with the $\mathrm{CSCHs}$, the maximum overshoot pressure of the NSCHs was reduced by $0.4 \mathrm{MPa}$ and the impact oscillation time was shortened by $4.13 \mathrm{~s}$, which plays a vital role in reducing vibration and absorbing energy.

In this paper, it was found that the phenomenon "tires off the ground" is related to the driving speed of vehicles. Next, more experimental speeds can be selected for the experiment, and more convex platforms with different heights can also be chosen to find more rules. In order to further improve the performance of the NSCHs, intelligent control elements can be added to make it become semiactive suspension or active suspension. The performance of the NSCHs was studied theoretically and experimentally. In the future, more studies can be carried out with the help of simulation software.

\section{Acknowledgements}

This research was supported in part by the Fundamental Research Funds for the Central Universities of China (Grant Nos. 300102258110, 310825171004 and 300102258109), the Natural Science Basic Research Project of Shaanxi Province, China (Grant No. 2019JM073) and the China Postdoctoral Science Foundation (Grant No. 2018M633439).

\section{REFERENCES}

[1] Cutini, M., Costa, C., \& Bisaglia, C. (2016). Development of a simplified method for evaluating agricultural tractor's operator whole body vibration. Journal of Terramechanics, 63(2), 23-32. https://doi.org/10.1016/j.jterra.2015.11.001

[2] Zhao, Y., Xu, H., Deng, Y., \& Wang, Q. (2018). Multiobjective optimization for ride comfort of hydro-pneumatic suspension vehicles with mechanical elastic wheel. Proceedings of the Institution of Mechanical Engineers, 233(11), 2714-2728. https://doi.org/10.1177/0954407018804909

[3] Melzi, S., Negrini, S., \& Sabbioni, E. (2014). Numerical analysis of the effect of tire characteristics, soil response and suspensions tuning on the comfort of an agricultural vehicle. Journal of Terramechanics, 55, 17-27. https://doi.org/10.1016/j.jterra.2014.05.001

[4] Adam, S. A. \& Jalil, N. A. A. (2017). Vertical suspension seat transmissibility and seat values for seated person exposed to whole-body vibration in agricultural tractor preliminary study. Procedia Engineering, 170, 435e 442. https://doi.org/10.1016/j.proeng.2017.03.070

[5] Mitra, A. C., Desai, G. J., Patwardhan, S. R., Shirke, P. H., Kurne, W. M., \& Banerjee, N. (2016). Optimization of Passive Vehicle Suspension System by Genetic Algorithm. Procedia Engineering, 144(144), 1158-1166. https://doi.org/10.1016/j.proeng.2016.05.087

[6] Sim, K., Lee, H., Yoon, J. W., Choi, C., \& Hwang, S. H. (2017). Effectiveness evaluation of hydro-pneumatic and semi-active cab suspension for the improvement of ride comfort of agricultural tractors. Journal of Terramechanics, 69(2), 23-32. https://doi.org/10.1016/j.jterra.2016.10.003

[7] Zehsaz, M., Sadeghi, M. H., Ettefagh, M. M., \& Shams, F. (2011). Tractor cabin's passive suspension parameters optimization via experimental and numerical methods. Journal of Terramechanics, 48(6), 439-450. https://doi.org/10.1016/j.jterra.2011.09.005

[8] Zheng, E., Zhong, X., Zhu, R., Xue, J., Cui, S., Gao, H., \& Lin, X. (2019). Investigation into the vibration characteristics of agricultural wheeled tractor-implement system with hydro-pneumatic suspension on the front axle. Biosystems Engineering, 186, 14-33. https://doi.org/10.1016/j.biosystemseng.2019.05.004

[9] Jugulkar, L. M., Singh, S., \& Sawant, S. M. (2016). Fluid flow modeling and experimental investigation on automobile damper. Construction and Building Materials, 121, 760-772. https://doi.org/10.1016/j.conbuildmat.2016.05.142

[10] Jugulkar, L. M., Singh, S., \& Sawant, S. M. (2016). Analysis of suspension with variable stiffness and variable damping force for automotive applications. Advances in Mechanical Engineering, 8(5), 8/5/1687814016648638. https://doi.org/10.1177/1687814016648638

[11] Ranjan, P., Bhola, M., Wrat, G., Mishra, S. K., \& Das, J. (2020). Performance enhancement of hybrid hydraulic excavator using multiple hydro-pneumatic accumulators. Proceedings of the Institution of Mechanical Engineers, Part I: Journal of Systems and Control Engineering. https://doi.org/10.1177/0959651820904274

[12] Yin, Y., Rakheja, S., Yang, J., \& Boileau, P. E. (2018). Characterization of a hydro-pneumatic suspension strut with gas-oil emulsion. Mechanical Systems and Signal Processing, 106, 319-333. https://doi.org/10.1016/i.ymssp.2017.12.040

[13] Yin, Y., Rakheja, S., Yang, J., \& Lozano-Guzman, A. (2020). Hydraulic damping nonlinearity of a compact hydropneumatic suspension considering gas-oil emulsion. Vibroengineering PROCEDIA, 30, 68-71. https://doi.org/10.21595/vp.2019.20715

[14] Francois, V. D. W. S., \& Schalk Els, P. (2015). Comparison of different gas models to calculate the spring force of a 
hydropneumatic suspension. Journal of Terramechanics, 57, 41-59. https://doi.org/10.1016/j.jerra.2014.11.002

[15] Kwon, K., Seo, M., Kim, H., Lee, T. H., Lee, J., \& Min, S. (2019). Multi-objective optimisation of hydro-pneumatic suspension with gas-oil emulsion for heavy-duty vehicles. Vehicle System Dynamics, 1-20. https://doi.org/10.1080/00423114.2019.1609050

[16] Arikan, K. B., Kucuk, K., Yurt, H. K., \& Imrek, H. (2016). Modelling and optimisation of an $8 \times 8$ heavy duty vehicle's hydro-pneumatic suspension system. International Journal of Vehicle Design, 71, 122-138. https://doi.org/10.1504/IJVD.2016.078772

[17] Solomon, U. \& Padmanabhan, C. (2011). Semi-active hydrogas suspension system for a tracked vehicle. Journal of Terramechanics, 48(3), 225-239. https://doi.org/10.1016/j.jterra.2011.01.002

[18] Danish, A. \& Samuel, F. (2018). Artificial intelligence models for predicting the performance of hydro-pneumatic suspension struts in large capacity dump trucks. International Journal of Industrial Ergonomics, 67, 283-295. https://doi.org/10.1016/j.ergon.2018.06.005

[19] Mačužić, S., Lukić, J., \& Ružić, D. (2018). Threedimensional simulation of the mcpherson suspension system. Tehnicki vjesnik - Technical Gazette, 25(5), 1286-1290. https://doi.org/10.17559/TV-20161215093920

[20] Kwon, K., Seo, M., Kim, H., Lee, T. H., Lee, J., \& Min, S. (2020). Multi-objective optimisation of hydro-pneumatic suspension with gas-oil emulsion for heavy-duty vehicles. Vehicle System Dynamics, 58(7), 1146-1165. https://doi.org/10.1080/00423114.2019.1609050

[21] Ali, D. \& Frimpong, S. (2018). Impulse Force Reductions and Their Effects on WBV Exposures in High Impact Shovel Loading Operations. International Journal of Mining Science and Technology, 28(3), 423-435. https://doi.org/10.1016/j.ijmst.2018.03.007

[22] Ali, D. \& Frimpong, S., (2017). Virtual simulation of high impact shovel loading operation for optimum dumping characterization. Journal of Powder Metallurgy \& Mining, 6, $1-9$.

[23] Yi, T., Ma, F., Jin, C., \& Huang, Y. (2018). A novel coupled hydro-pneumatic energy storage system for hybrid mining trucks. Energy, 143, 704-718. https://doi.org/10.1016/j.energy.2017.10.131

[24] Wu, W., Zhang, S., \& Zhang, Z. (2019). Mathematical Simulations and On-Road Experimentations of the Vibration Energy Harvesting from Mining Dump Truck HydroPneumatic Suspension. Shock and Vibration, 2019, 1-16. https://doi.org/10.1155/2019/4814072

[25] Cuong, D. M., Zhu, S., \& Zhu, Y. (2013). Effects of tyre inflation pressure and forward speed on vibration of an unsuspended tractor. Journal of Terramechanics, 50(3), 185198. https://doi.org/10.1016/j.jterra.2013.05.001

[26] Yuan, J. Q., Zhu, S. H., Gao, Q., Xu, G., Ma, J. F., \& Lu, Z. $X$. (2017).Design and characteristic study of tractor front axle hydro-pneumaticspring. Journal of Nanjing Agricultural University, 40(1), 176e185.

[27] Britsin, S., Ryabinin, M., \& Sarach, E. (2020). Calculation of the hydro-pneumatic suspension damper. IOP Conference Series Material Science and Engineering, 779, 012033. https://doi.org/10.1088/1757-899X/779/1/012033

[28] Yang, J., Yin, Y., Rakheja, S., Chu, S., Chen, C., \& Zhang, W. (2019). Mechanics characteristics of a kind of hydra pneumatic suspension. Nonlinear Dynamics, 95(2), 407-419. https://doi.org/10.1007/s11071-018-4572-8

\section{Contact information:}

Xuefeng SUO, PhD Candidate

(Corresponding author)

Key Laboratory of Road Construction Technology and Equipment of MOE School of Construction Machinery, Chang'an University,

Middle Section of South Second Ring Road, Xi'an 710064, P. R. China

E-mail: suoxuefeng@chd.edu.cn

Shengjie JIAO, PhD, Prof.

Key Laboratory of Road Construction Technology and Equipment of MOE, School of Construction Machinery, Chang'an University,

Middle Section of South Second Ring Road, Xi'an 710064, P. R. China

E-mail: jsj@chd.edu.cn

\section{Gangfeng WANG, PhD}

Key Laboratory of Road Construction Technology and Equipment of MOE, School of Construction Machinery, Chang'an University,

Middle Section of South Second Ring Road, Xi'an 710064, P. R. China

E-mail: wanggf@chd.edu.cn

\section{Simeng LIU, PhD}

Key Laboratory of Road Construction Technology and Equipment of MOE School of Construction Machinery, Chang'an University,

Middle Section of South Second Ring Road, Xi'an 710064, P. R. China

E-mail: liusimeng@chd.edu.cn

\section{Zeyu ZHANG, PhD}

Key Laboratory of Road Construction Technology and Equipment of MOE, School of Construction Machinery, Chang'an University,

Middle Section of South Second Ring Road, X''an 710064, P. R. China

E-mail: zhangzeyu@chd.edu.cn 